2014

\title{
Voltage Smoothing with a Capacitor
}

Martin Copello

University of South Florida

\author{
Advisors: \\ Arcadii Grinshpan, Mathematics and Statistics \\ Scott Campbell, Chemical \& Biomedical Engineering \\ Problem Suggested By: Scott Campbell
}

Follow this and additional works at: https://digitalcommons.usf.edu/ujmm

Part of the Electrical and Electronics Commons, and the Mathematics Commons

UJMM is an open access journal, free to authors and readers, and relies on your support:

Donate Now

\section{Recommended Citation}

Copello, Martin (2014) "Voltage Smoothing with a Capacitor," Undergraduate Journal of Mathematical

Modeling: One + Two: Vol. 5: Iss. 2, Article 2.

DOI: http://dx.doi.org/10.5038/2326-3652.5.2.2

Available at: https://digitalcommons.usf.edu/ujmm/vol5/iss $2 / 2$ 


\title{
Voltage Smoothing with a Capacitor
}

\begin{abstract}
A rectifier is an electrical circuit that converts alternating current to direct current, e.g., a half wave rectifier removes lower valleys of the $\mathrm{AC}$ voltage wave. If a capacitor is placed in parallel with a half wave rectifier, the transition from voltage peak to peak is smoothed to closer resemble constant DC voltage. The objective of this project was to model the voltage changes of a half wave rectifier with a parallel capacitor. It was found that the smoothness of the voltage waves increased as the capacitance of the capacitor increased.
\end{abstract}

Keywords

AC/DC Converter, Rectifier, Voltage smoothing, Parallel Capacitor

Creative Commons License

(c) (i) ()

This work is licensed under a Creative Commons Attribution-Noncommercial-Share Alike 4.0 License. 


\section{PROBLEM STATEMENT}

A half wave rectifier converts AC current to DC current - which is now unidirectional but still varies with time, as shown in the Figure 1. For particular applications, it may be important that the variation in voltage with time be much smaller than that of the rectified wave.

V

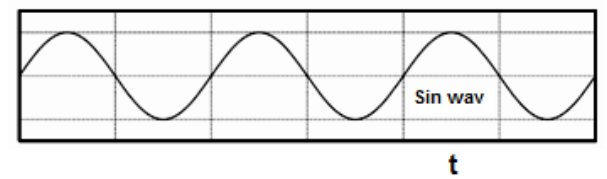

V

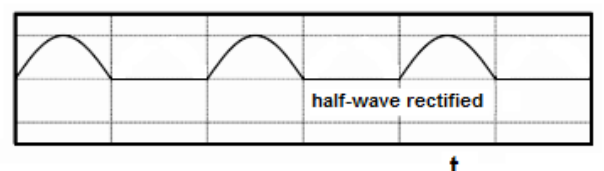

Figure 1: Half wave rectified signal.

One way to smooth the half wave rectified voltage is to place a capacitor in parallel with the load, as shown in the circuit below where $R_{L}$ represents the resistance of the load:

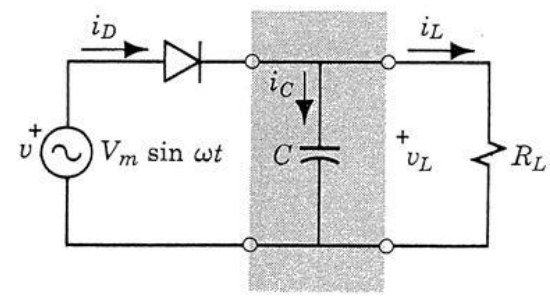

(a) Circuit

Figure 2: Circuit for smooth half wave rectifier.

Without the capacitor, the load voltage $v_{L}$ would look like the bottom graph of Figure 1 . By adding the capacitor, the load voltage $v_{L}$ is smoothed and looks as Figure 3: 


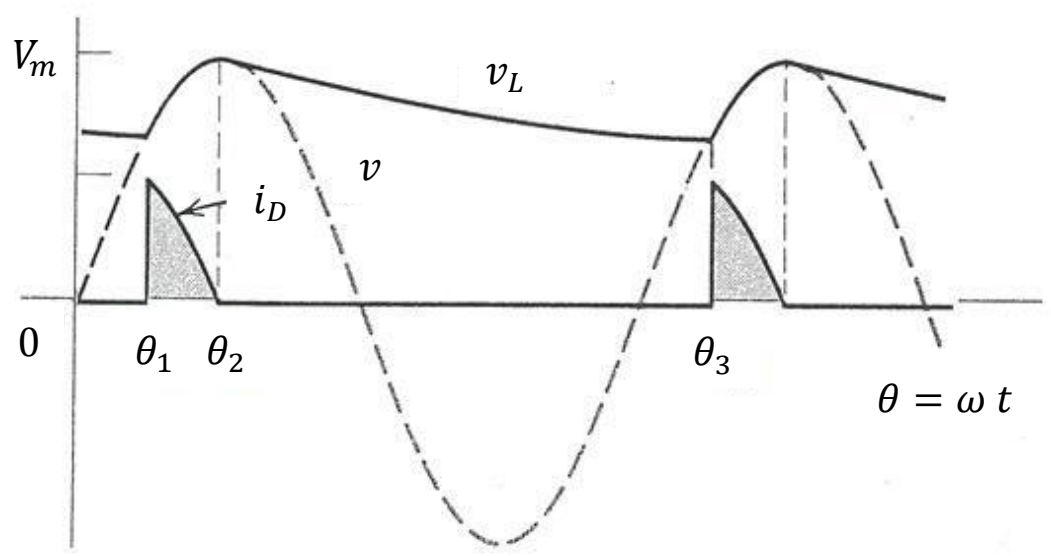

Figure 3: Voltage and current waveforms

The goal of this project is to quantify the behavior of the load voltage $v_{L}$ for a given capacitance $C$ and to examine the degree to which the capacitance can smooth the load voltage. The behavior of the circuit is governed by the following equations. When the diode passes current (for $\theta_{1}<\theta<\theta_{2}$ ), the load voltage is the same as the source voltage:

$$
v_{L}=V_{m} \sin \theta
$$

where $\theta=\omega t$ ( $\omega$ is the frequency of the voltage source) and $V_{m}$ is the maximum voltage.

When the diode does not pass current (for $\theta_{2}<\theta<\theta_{3}$ ), the behavior of the circuit is governed by:

$$
R_{L} C \frac{d v_{L}}{d x}+v_{L}=0
$$

where $R_{L}$ is the resistance of the load in $\Omega(\mathrm{Ohms})$ and $C$ is the capacitance in $F$ (Farads). Note that $\theta_{3}=\theta_{1}+2 \pi$ and $\theta_{2}=\frac{\pi}{2}$. Suppose that the frequency of the voltage source is $377 \mathrm{rad} / \mathrm{s}$ (corresponding to 60 cycles/sec) and the load resistance is $4,000 \Omega$. Plot the load voltage $v_{L}$ versus $\theta$ for two different cases - one in which the capacitance is $50 \times 10^{-6} \mathrm{~F}$ and one for which it is $5 \times 10^{-6} \mathrm{~F}$. 


\section{MOTIVATION}

Alternating current (AC) can be converted into direct current (DC) by using a half wave rectifier. However, after converting to direct current, only the half of the original signal is passed to the next stage, giving a large variation of voltage with time (ripples). Most electronic applications required DC voltage with a smoother change in voltage. In order to smooth these changes (ripples), a capacitor is placed in parallel with the load voltage. The motivation of this project is to find the dependence of the capacitance value on the smoothing process.

\section{MATHEMATICAL DESCRIPTION AND SOLUTION APPROACH}

Graphical approach was selected to solve the given problem. First, the given differential equation for $v_{L}$ for the range $\theta_{2}<\theta<\theta_{3}$ integrated to find an equation of $v_{L}$ between $\theta_{2}$ and $\theta_{3}$.

$$
R_{L} C \frac{d v_{L}}{d t}+v_{L}=0
$$

Simplifying (3) to separate and integrating both sides gives,

$$
\int \frac{d v_{L}}{v_{L}}=-\int \frac{d t}{R_{L} C}
$$

i.e.,

$$
\ln \left|v_{L}\right|=-\frac{t}{R_{L} C}+\ln k
$$

where $k$ is some unknown constant. Solving for $v_{L}$ for $\theta_{2}<\theta<\theta_{3}$ : 


$$
v_{L}=k e^{\left(\frac{-t}{R_{L} C}\right)}
$$

The frequency of the voltage source is given as $377 \mathrm{rad} / \mathrm{sec}$ (corresponding to 60 cycles/sec). The time and $\theta$ are related by,

$$
\theta=\omega t
$$

and, considering both formulas for the voltage, we note that at $\theta=\frac{\pi}{2}$, where both curves given in (1) and (2) intersects. At $\theta=\frac{\pi}{2}$, equation (1) becomes $v_{L}=V_{m}$, equation (7) becomes $t=\frac{\theta}{\omega}=$ $\frac{\pi}{2 \omega}$, and solving for $k$ in (6) gives

$$
k=V_{m} \exp \left\{\frac{\pi}{2 \omega R_{L} C}\right\} .
$$

and in general over the interval $\left[\theta_{1}, \theta_{3}\right)$ :

$$
v_{L}=\left\{\begin{array}{cl}
V_{m} \sin \theta, & 0<\theta_{1} \leq \theta<\theta_{2}=\frac{\pi}{2} ; \\
V_{m} \exp \left\{\frac{\frac{\pi}{2}-\theta}{\omega R_{L} C}\right\}, & \frac{\pi}{2}=\theta_{2} \leq \theta<\theta_{3} \leq \frac{5 \pi}{2} .
\end{array}\right.
$$

Recall that $\theta_{1}=\theta_{3}-2 \pi$, but it remains to compute $\theta_{3}$. However $\theta_{3}$ is the solution to

$$
V_{m} \sin \theta=V_{m} \exp \left\{\frac{\frac{\pi}{2}-\theta}{\omega R_{L} C}\right\}
$$

for some $\frac{\pi}{2}<\theta \leq \frac{5 \pi}{2}$. Taking $\omega=377 \frac{\mathrm{rads}}{\mathrm{s}}, R_{L}=4,000 \Omega, C=50 \times 10^{-6} \frac{\mathrm{s}}{\Omega}$, and $V_{m}=1 \mathrm{~V}$, Excel computes that $\theta_{3} \approx 7.463748$ (see Figure 4). It should be noted that this solution does not depend on $V_{m}$ as it can be divided through on both sides of (10). 


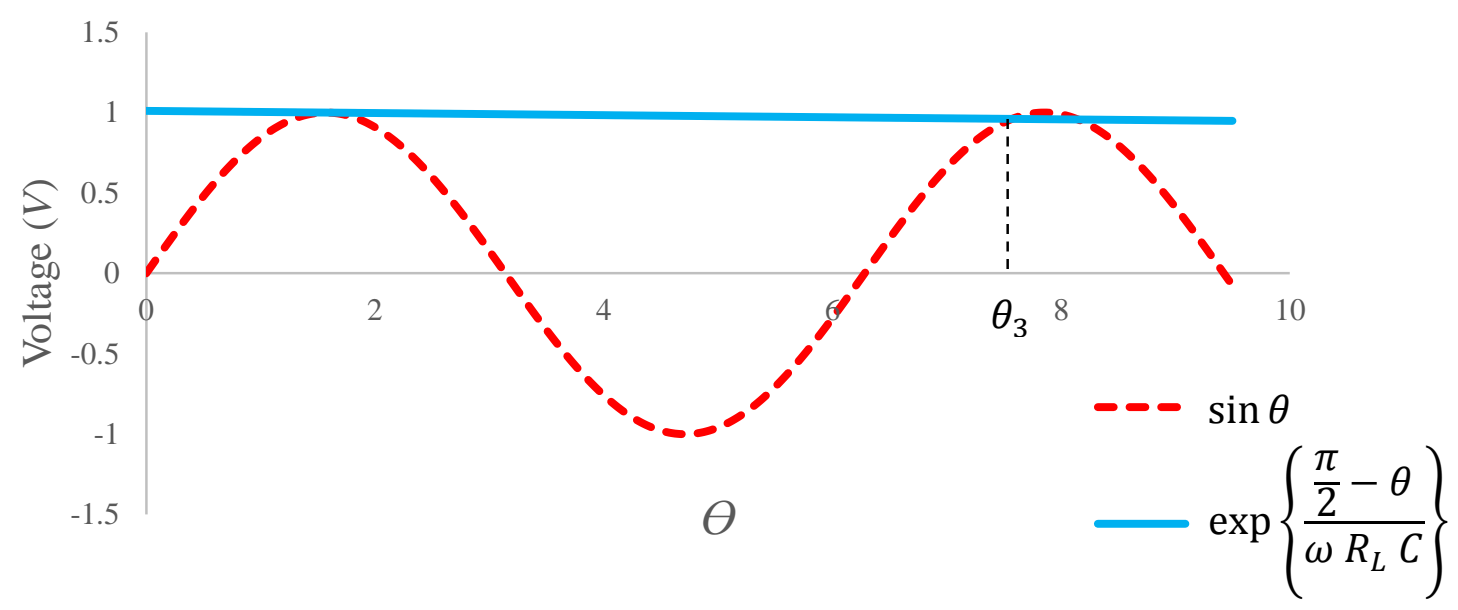

Figure 4: Voltage $v_{L}$ across the load and input sine wave.

This single period can be generalized from (9) to describe the entire solution as:

$$
v_{L}=\left\{\begin{array}{cc}
V_{m} \exp \left\{\frac{\frac{\pi}{2}-\theta}{\omega R_{L} C}\right\}, & 0 \leq \theta(\bmod 2 \pi)<\theta_{1} ; \\
V_{m} \sin \theta, & \theta_{1} \leq \theta(\bmod 2 \pi)<\frac{\pi}{2} ; \\
V_{m} \exp \left\{\frac{\frac{\pi}{2}-\theta}{\omega R_{L} C}\right\} & \frac{\pi}{2} \leq \theta(\bmod 2 \pi)<2 \pi ;
\end{array}\right.
$$

where $\theta_{1} \approx 1.1806$ (see Figure 5 ).

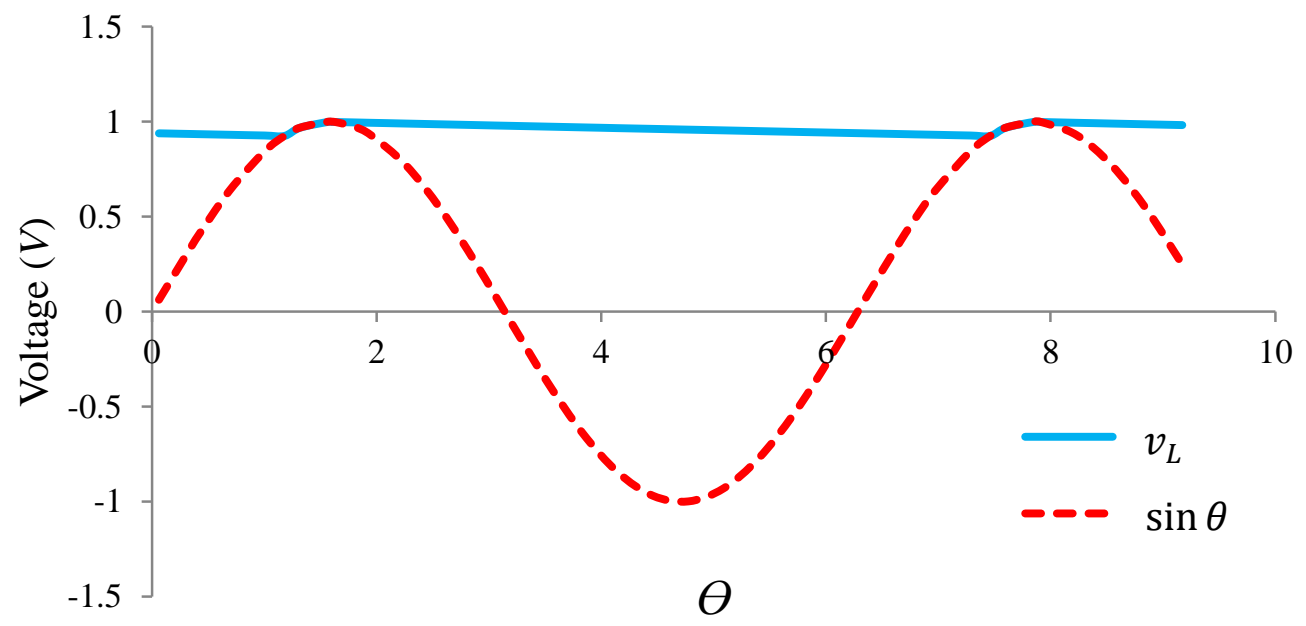

Figure 5: Load voltage $v_{L}$ with $C=50 \times 10^{-6} F$ and the sine wave. 
If instead the capacitance $C$ is decreased to $5 \times 10^{-6} F$, the voltage across the load can again be calculated using the same method as before to find that $\theta_{1} \approx 0.5229$ (see Figure 6).

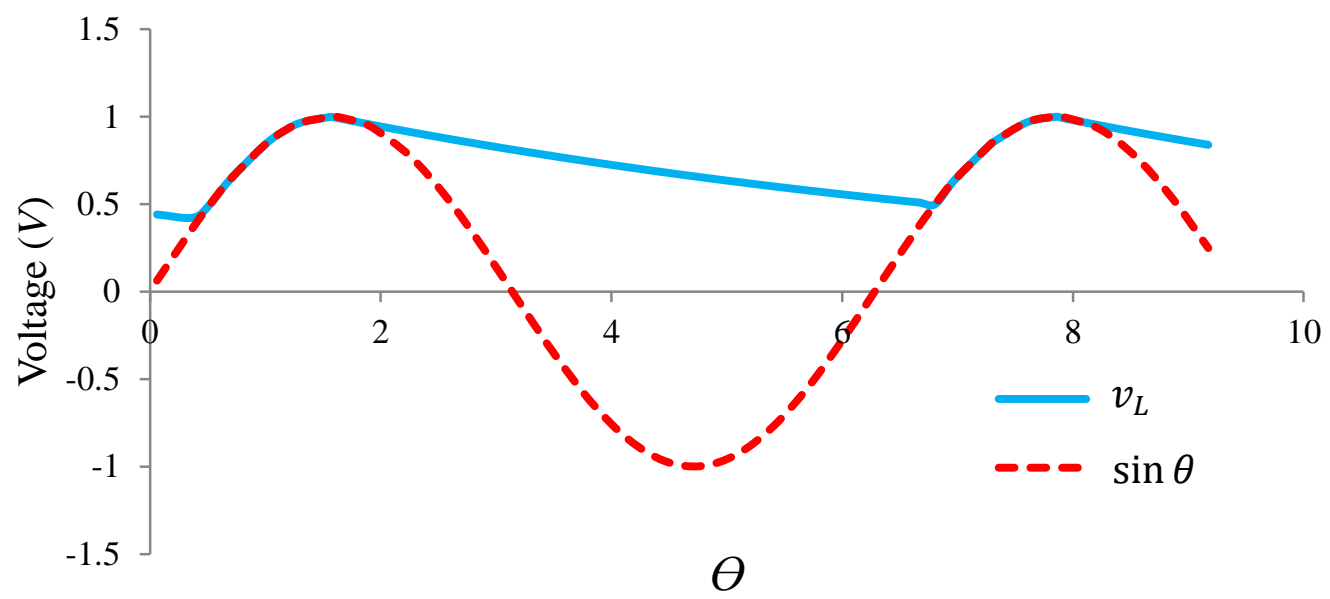

Figure 6: Load voltage $v_{L}$ with $C=5 \times 10^{-6} F$ and the sine wave.

After examining both graphs, we were able to determine that as the capacitance of the parallel capacitor increases, the degree of smoothing of the graph increases. This means we need to use higher capacitance value for parallel capacitor in order to obtain better smoothed voltage.

\section{DISCUSSION}

We were able to meet the objectives of the project, and we managed to not only quantify the behavior of the voltage when a capacitor is added to the circuit, but also to calculate the average load voltage for each case. Our results show that the bigger the capacitance of the parallel capacitor added, the smoother the voltage will become.

\section{CONCLUSION AND RECOMMENDATIONS}

This project helped us study the effect of capacitors on rectifier circuits. Voltage ripple can be smoothed by adding parallel capacitors across the load in a rectifier circuit. The degree of smoothness increases when the capacitance increases. 


\section{NOMENCLATURE}

\begin{tabular}{|l|l|l|}
\hline Symbol & Magnitude & Units \\
\hline$\omega$ & Frequency & Radians per Seconds (rad/s) \\
\hline$R_{L}$ & Load Resistance & Ohms $(\Omega)$ \\
\hline$C$ & Capacitance & Farads (F) \\
\hline$V_{L}$ & Load Voltage & Volts (V) \\
\hline
\end{tabular}

\section{REFERENCES}

James Stewart. Essential Calculus: Early Transcendental, 1st Edition Brooks Cole, 2006.

Raymond. A Serway, and John W. Jewett JR. Physics for Scientists and Engineers with Modern Physics. 8th Edition, Brooks Cole, 2010.

Kent Nagle, Edward B. Saff and Arthur David Snider, Fundamentals of Differential Equations, 8th Edition, Addison-Wesley, Pearson, 2011.

Allan R. Hambley. Electrical Engineering Principles and Applications. 5th Edition. Prentice Hall, Pearson, 2010. 